\title{
The potential of Fourier transform infrared spectroscopy of milk samples to predict energy intake and efficiency in dairy cows ${ }^{1}$
}

\author{
S. McParland ${ }^{2}$ and D. P. Berry \\ Animal and Grassland Research and Innovation Center, Teagasc, Moorepark, Fermoy, Co. Cork, Ireland
}

\begin{abstract}
Knowledge of animal-level and herd-level energy intake, energy balance, and feed efficiency affect dayto-day herd management strategies; information on these traits at an individual animal level is also useful in animal breeding programs. A paucity of data (especially at the individual cow level), of feed intake in particular, hinders the inclusion of such attributes in herd management decision-support tools and breeding programs. Dairy producers have access to an individual cow milk sample at least once daily during lactation, and consequently any low-cost phenotyping strategy should consider exploiting measureable properties in this biological sample, reflecting the physiological status and performance of the cow. Infrared spectroscopy is the study of the interaction of an electromagnetic wave with matter and it is used globally to predict milk quality parameters on routinely acquired individual cow milk samples and bulk tank samples. Thus, exploiting infrared spectroscopy in next-generation phenotyping will ensure potentially rapid application globally with a negligible additional implementation cost as the infrastructure already exists. Fourier-transform infrared spectroscopy (FTIRS) analysis is already used to predict milk fat and protein concentrations, the ratio of which has been proposed as an indicator of energy balance. Milk FTIRS is also able to predict the concentration of various fatty acids in milk, the composition of which is known to change when body tissue is mobilized; that is, when the cow is in negative energy balance. Energy balance is mathematically very similar to residual energy intake (REI), a suggested measure of feed efficiency. Therefore, the prediction of energy intake, energy balance, and feed efficiency (i.e., REI) from milk FTIRS seems logical. In fact, the accuracy of predicting (i.e., correlation between predicted and actual values; root
\end{abstract}

Received July 2, 2015.

Accepted January 14, 2016.

${ }^{1}$ Presented as part of the Joint Interbull JAM Symposium: Milk Spectral Data - Cost-Effective Information to Improve Expensive and Limited Traits in Dairy Cattle Breeding at the ADSA-ASAS Joint Annual Meeting, Orlando, Florida, July 2015.

${ }^{2}$ Corresponding author: sinead.mcparland@teagasc.ie mean square error in parentheses) energy intake, energy balance, and REI from milk FTIRS in dairy cows was $0.88(20.0 \mathrm{MJ}), 0.78$ (18.6 MJ), and 0.63 (22.0 MJ), respectively, based on cross-validation. These studies, however, are limited to results from one research group based on data from 2 contrasting production systems in the United Kingdom and Ireland and would need to be replicated, especially in a range of production systems because the prediction equations are not accurate when the variability used in validation is not represented in the calibration data set. Heritable genetic variation exists for all predicted traits. Phenotypic differences in energy intake also exists among animals stratified based on genetic merit for energy intake predicted from milk FTIRS, substantiating the usefulness of such FTIR-predicted phenotypes not only for day-to-day herd management, but also as part of a breeding strategy to improve cow performance.

Key words: spectroscopy, energy intake, residual feed intake, efficiency, chemometrics

\section{INTRODUCTION}

Efficient and effective day-to-day herd management requires real-time access to accurate and useful data from a range of different sources to aid in making informed decisions. Such data sources may reflect the quantity and quality of feed (e.g., DM digestibility of grass in grazing production systems), the prevailing environmental conditions (i.e., temperature and humidity of the housing infrastructure or predicted weather conditions), as well as the physiological state and performance of each individual cow or the herd as a whole. Real-time, within-unit (i.e., cow or herd), temporal deviations can be useful to evaluate recent management changes, preempt situations that may require remedial action, and modify decision-support tools to determine what actions, if any, need to be taken. Also considered within the realm of decision-support tools is the recommended germplasm to improve certain performance characteristics at an individual animal level; not only do such decisions require knowledge on the performance characteristics of the individual female, they also require accurate information on the genetic 
merit of the candidate mates. Accurate genetic (and genomic) evaluations depend on routine access to large quantities of phenotypic information on the animal itself or its relatives from which to derive genetic (and genomic) evaluations for the performance characteristics of interest (Daetwyler et al., 2008).

The dairy cattle production system is a rather unique livestock production system in that access exists, usually 2 to 3 times daily, to a biological sample (i.e., milk) that could be used to reveal the physiological state of each cow. Most, if not all, of the major constituents in milk are synthesized in the mammary gland derived from precursors absorbed from the blood. For example, fatty acids in milk originate either from chylomicrons and very low density lipoproteins in blood or are synthesized from acetate derived from circulating blood acetate. Metabolomic and proteomic interrogation of dairy cow milk has identified a plethora of compounds (Klein et al., 2012; Lu et al., 2013) and several have been hypothesized to be useful predictors of cow health and performance (Klein et al., 2012; Lu et al., 2013). Thus, the analysis of milk routinely harvested in dairy production systems provides a rich source of potentially useful phenotypes to aid in day-to-day farm management and breeding decisions. This review focuses specifically on the potential of infrared spectroscopy of milk to generate useful animal-level phenotypes, in particular energy intake and efficiency; infrared spectroscopy was chosen because this technology is already used globally to routinely quantify milk quality parameters in milk samples and thus any discoveries can be readily implemented at negligible additional cost. Such milk samples originate from individual cows but also herd bulk tank samples.

\section{INFRARED SPECTROSCOPY}

Spectroscopy may be defined as the study of the interaction of an electromagnetic wave with matter. All spectroscopic methods, with the exception of mass spectroscopy, may be classified based on the energy used in the measurement approach. Electromagnetic radiation involves waves being transmitted from a source, traveling in a straight line until the waves encounter matter, at which time they may be either reflected or refracted. Vibrational movements of molecules affect absorbance in the infrared region, which can be subsequently detected by spectrometers as absorbance bands. The infrared radiation can also induce rotational movements of the molecules, resulting in rotational bands. Chemometrics is the process of extracting information from chemical systems using data-mining techniques relating the spectral data to phenotypes.
Two types of spectroscopy commonly used in the agri-food industry are near-infrared (NIRS) and midinfrared (MIRS) spectroscopy, which differ simply in the region of the electromagnetic spectrum considered. Absorbance by matter of light in the mid-infrared (MIR) region corresponds to fundamental bands of molecular vibrations, whereas absorbance in the nearinfrared (NIR) region corresponds to overtones and combinations of these fundamental bands (Williams and Norris, 1987). The consequences of this difference are that (1) the absorbance coefficients are considerably smaller in the NIR range, which allows light to better penetrate into the matter, and (2) the NIR spectrum can be overloaded with information because of the abundance of combination and overtone bands. Hence, the specificity of bands is reduced in the NIR region compared with the MIR region. Moreover, the spectrum in the NIR region is more affected by factors that affect the diffusion of light, such as the physical structure and the presence of water (Williams and Norris, 1987). Infrared spectroscopy has been successfully used in the quantification of agriculturally important compounds in various sample types, including animal feed (Edney et al., 1994), meat (Kamruzzaman et al., 2012), soil (Hummel et al., 2001), and milk (Soyeurt et al., 2011).

\section{Infrared Spectroscopy to Predict Milk Quality}

The usefulness of FTIRS, particularly in the MIR region, to predict various milk quality parameters has been discussed in detail elsewhere (Berry et al., 2013a; De Marchi et al., 2014). Moreover, FTIRS is used globally for routine quantification of, at the very least, total fat, total protein, and lactose concentrations in milk (Luinge et al., 1993). Recent studies have documented the ability of FTIRS to predict individual fatty acids and groups of milk fatty acids with moderate to high accuracy (Figure 1; Rutten et al., 2009; Soyeurt et al., 2011; Maurice-Van Eijndhoven et al., 2013); milk technological traits such as milk coagulation properties (Dal Zotto et al., 2008; De Marchi et al., 2009; Visentin et al., 2015), and milk titratable acidity (Toffanin et al., 2014; Visentin et al., 2015) with moderate accuracy; and milk minerals (Soyeurt et al., 2009; Toffanin et al., 2014), individual milk proteins (Bonfatti et al., 2011; Rutten et al., 2011; McDermott et al., 2016), and free amino acids (McDermott et al., 2016) with low to moderate accuracy. A summary of the accuracy of FTIRS at predicting a selection of milk quality traits is presented in Figure 1. Although prediction accuracy is generally sufficient to use predicted traits in breeding programs, it is not sufficient for payment purposes, 


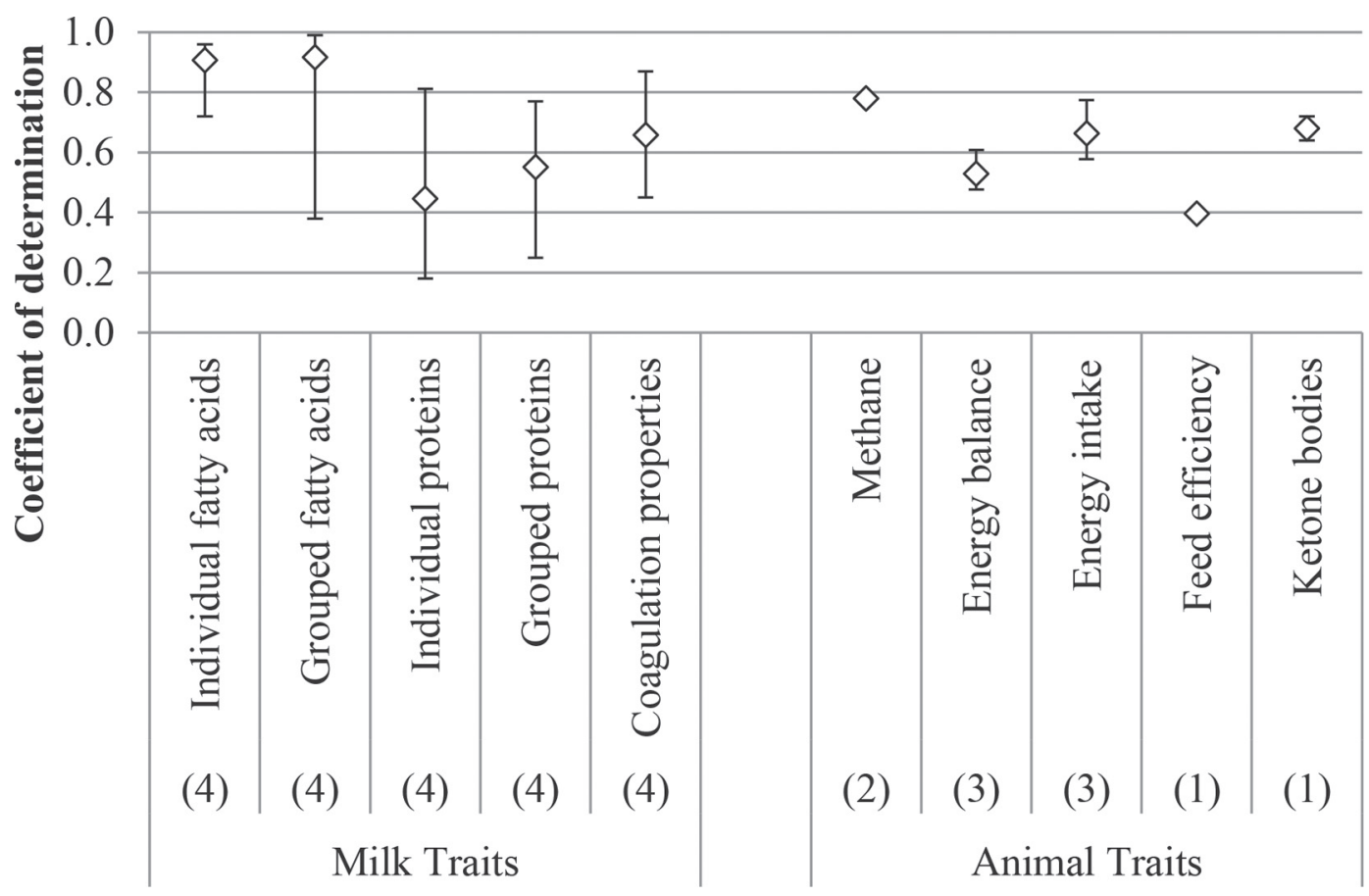

Figure 1. Coefficient of determination of cross validation for prediction of milk and animal phenotypes across recent studies. The maximum coefficient of determination reported in each study was used to generate the (unweighted) average across studies. Error bars represent the maximum and minimum coefficient of determination obtained across studies. Values in parentheses correspond to the number of studies included in the average statistic. Details on grouped traits and references for studies are included in the supplementary file (http://dx.doi.org/10.3168/ jds.2015-10051).

particularly in the case of milk proteins, free amino acids, and minerals.

The equipment necessary to undertake MIR analysis of milk is expensive but its high throughput (up to 500 samples per hour) translates to a low cost per sample. The equipment for analyzing milk in the NIR region is, however, less expensive and thus amenable for routine use, potentially on-farm. Coppa et al. (2014) documented good predictive ability of milk fatty acid content using NIR (and MIR) on fresh milk samples.

\section{Infrared Spectroscopy to Predict Animal Characteristics}

Few studies, to date, have evaluated the potential of infrared spectroscopy to predict animal-related characteristics. These studies have been solely confined to FTIR analysis of milk samples, and no study to date has evaluated the potential of NIR analysis of milk samples to predict animal characteristics, even though it has been recently shown (Coppa et al., 2014) that NIR can provide useful predictions of milk fatty acid content. Animal studies using milk FTIR have been mainly limited to predicting body energy status (McParland et al., 2011, 2012, 2014), energy intake (McParland et al., 2011, 2012, 2014), methane emissions (Dehareng et al.,
2012; Vanlierde et al., 2015), feed efficiency (McParland et al., 2014), risk of ketosis (de Roos et al., 2007), and likelihood of conception (Hempstalk et al., 2015). Of these animal phenotypes, the accuracy of prediction from FTIR was greatest for methane emissions, milk acetone, and energy intake, with coefficients of determination in cross validation in the range from 0.72 to 0.79 (Figure 1; de Roos et al., 2007; Dehareng et al., 2012; McParland et al., 2012).

Milk fat-to-protein ratio is commonly cited as an indicator of energy balance in dairy cows (Grieve et al., 1986; Friggens et al., 2007), although recent analysis at an individual cow level brings into question the usefulness of this ratio as a proxy for energy balance (McParland et al., 2011). The accuracy of predicting energy balance directly in an external validation data set from just test-day milk, fat, protein, and lactose yields was poor at 0.38 (McParland et al., 2014); the external validation animals used, although different animals to those used in the development of the calibration equations, were generally managed within the same production system. Nonetheless, high milk fat relative to protein content is hypothesized as an indicator of negative energy balance because cows mobilize body reserves in the form of triglycerides to fulfill the energy requirement of lactation. A proportion of 
the triglycerides enter the milk, causing the milk fat concentration to increase. The ability of milk FTIR to predict milk fat and protein concentration is well established (Luinge et al., 1993); thus, it seems plausible that the FTIR analysis of milk should indeed be able to predict cow energy status.

Mobilization of adipose fatty acids during a period of negative energy balance results in an increase in the concentration of C18 fatty acid in milk and a consequent inhibition of de novo synthesis of fatty acids by the mammary gland (Palmquist et al., 1993; Barber et al., 1997). The ability of FTIR analysis of milk to predict milk fatty acid content (Rutten et al., 2009; Soyeurt et al., 2011; Maurice-Van Eijndhoven et al., 2013) further substantiates why FTIRS should indeed be useful to predict cow energy status (including energy intake). Moreover, the ability to differentiate between different fatty acids in milk suggests that the FTIR spectrum itself should be a better predictor of energy balance than simply fat-to-protein ratio or fatty acid concentration alone. Additionally, the presence of ketone bodies in milk is thought to reflect negative energy balance (Reist et al., 2002). Several studies have documented the ability of FTIR analysis of milk to predict acetone, acetoacetate, and $\beta$-hydroxybutyrate (Hansen, 1999; Heuer et al., 2001; de Roos et al., 2007), the presence of which are known to be associated with ketosis. Therefore, a strong biological rationale exists as to why energy balance (and energy intake) can be predicted from milk FTIR.

Two studies have documented the ability of the FTIR spectrum to predict methane emissions in dairy cows (Dehareng et al., 2012; Vanlierde et al., 2015). Those studies hypothesized that the change in milk fatty acid profile, which can be predicted from the FTIR spectrum, may be linked to eructed methane emissions. This link materializes from ruminal fermentation resulting in the production of de novo milk fatty acids as well as eructation of methane emissions (Chilliard et al., 2001). By incorporating stage of lactation into the prediction model, Vanlierde et al. (2015) indirectly accounted for metabolic status and thus improved the lactation profile of predicted eructed methane.

\section{WHY IS FEED EFFICIENCY PREDICTABLE FROM INFRARED ANALYSIS OF MILK?}

Energy balance (EB) may be defined as the difference between energy intake and energy output; energy output generally includes energy for milk production, body maintenance (approximated) from metabolic live weight, growth, and pregnancy:
Energy balance $=\mathrm{E}_{\mathrm{INTAKE}}-\left(\mathrm{E}_{\mathrm{MILK}}+\mathrm{E}_{\text {MAINTENANCE }}\right.$

$$
+\mathrm{E}_{\text {GROWTH }}+\mathrm{E}_{\text {PREGNANCY }} \text {, }
$$

where $\mathrm{E}_{\text {INTAKE }}=$ energy intake, $\mathrm{E}_{\mathrm{MILK}}=$ energy cost of lactation, $\mathrm{E}_{\text {MAINTENANCE }}=$ energy cost of maintenance, $\mathrm{E}_{\mathrm{GROWTH}}=$ energy cost of growth, and $\mathrm{E}_{\text {PREGNANCY }}=$ energy cost of pregnancy. The respective energy demands and costs of the different animal attributes are generally derived from nutritional tables (e.g., Jarrige et al., 1986; NRC, 2001), and EB may be defined in units of ME or net energy.

Residual energy intake (REI) is a commonly used definition of apparent feed efficiency in growing animals and it is growing in popularity in dairy cows (Berry and Crowley, 2013). Residual energy intake may be defined at the level of ME or net energy, and it can be defined as the difference between actual energy intake and predicted energy intake (Byerly, 1941). The expected energy intake per unit change in each of the energy sinks or sources of energy in the REI equation can be based on nutritional tables (e.g., Jarrige et al., 1986; NRC, 2001) such as those used to calculate EB; however, least squares regression analysis of the population under investigation is more commonly used to derive the required regression coefficients (Coleman et al., 2010; Hurley et al., 2016). Residual energy intake may be defined mathematically as

$$
\begin{gathered}
\mathrm{REI}=\mathrm{E}_{\text {INTAKe }}-\left(\mathrm{E}_{\mathrm{MILK}}+\mathrm{E}_{\text {MAINTENANCE }}+\mathrm{E}_{\mathrm{GROWTH}}\right. \\
\left.+\mathrm{E}_{\text {PREGNANCY }}\right)+\mathrm{E}_{\text {MOBILIZATion }},
\end{gathered}
$$

where $\mathrm{E}_{\text {MOBILIZATION }}=$ energy gained from body tissue mobilization, and the other terms are as defined previously.

The mathematical definitions of EB (equation [1]) and REI (equation [2]) are very similar, with the exception of the (last) term in the REI equation to account for the energy supplied from the mobilization of body reserves. Animals with higher energy output relative to energy intake (i.e., in negative energy balance) catabolize body energy to make up the energy deficit. Thus, the correlation between EB and REI is expected to be unity if the change in live weight is zero and both traits are derived using the same energy coefficients for each incremental change in the energy sinks; Hurley et al. (2016) reported a correlation of 0.96 between REI and EB in mid-lactation dairy cows when the change in live weight was close to zero. The strong relationship between EB and REI in lactating dairy cows is further substantiated by the strong similarity in lactation profile for each; both lactation profiles ascend in early lactation, reaching a plateau at approximately 
125 DIM (Hurley et al., 2016). The strong biological justification discussed earlier for being able to predict cow energy status from milk FTIR, coupled with the empirical evidence for predicting energy intake and EB from FTIR (McParland et al., 2011, 2012, 2014), implies that feed efficiency, or at least REI, could also be predicted from milk FTIR.

Methane emissions represent a loss of approximately $6 \%$ of ingested energy (Johnson and Johnson, 1995) and are therefore a likely contributing factor to differences among animals in feed efficiency. The aforementioned ability of FTIR analysis of milk to predict individual cow methane emissions (Dehareng et al., 2012; Vanlierde et al., 2015) further confirms the biological hypothesis as to how milk FTIR could indeed be used to predict feed efficiency in lactating dairy cows.

\section{OBSTACLES TO PREDICTION OF ENERGY INTAKE AND EFFICIENCY FROM MILK FTIR}

\section{The Link Between Milk Sample and Phenotype Is Not Direct}

Predicting animal phenotypes from the FTIR spectrum of an individual milk sample is less straightforward than predicting an explicit milk phenotype. Unlike the milk phenotype where the FTIR spectrum and gold standard test originate from the same sample (i.e., the same experimental unit usually measured under controlled laboratory conditions), animal phenotypes are indirectly linked to the FTIR via the milk sample. Typically, the animal phenotype (e.g., feed intake) is based on an average across a day or a week and is associated with the milk FTIR spectrum obtained from one or all milkings on the same day or during the same week as when the animal phenotypic value was generated (McParland et al., 2011). Moreover, the actual phenotype of an animal may not be reflected in the milk sample of that exact day, but in fact, the milk sample of (one of) the following days (e.g., the by-products from digestion of the energy ingested in a given day may not expressed in the milk of the cow until the following day) or a preceding day (e.g., conception; Hempstalk et al., 2015). As a means of representing the entire testday, Dehareng et al. (2012) used the average of the milk FTIR spectrum obtained from both a morning and an evening milking to predict methane emissions. However, Dehareng et al. (2012) noted that the time interval between the recording of the methane emission phenotype and the actual sampling of milk for FTIR analysis affected the accuracy of the subsequent prediction equation (Dehareng et al., 2012); the average FTIR spectrum of milk samples collected in the evening after the methane measurement, and the morning $2 \mathrm{~d}$ after methane measurement provided the most robust equation to predict methane emission (Dehareng et al., 2012). McParland et al. (2014) noted that the average of both the morning and evening milk FTIR spectra, either weighted by their respective milk yield or not, resulted in more accurate equations to predict energy intake and EB than prediction equations developed on the milk FTIR from either just the morning or just the evening milk sample.

\section{Accuracy of the Gold Standard Measure}

The accuracy of any prediction equation depends on the precision of measurement of the gold standard of the trait under investigation. Both feed efficiency and EB are index traits comprising individual animal intake, live weight, predicted milk composition (from FTIR), and maintenance requirements, as well as subjectively scored BCS (Berry et al., 2006; Berry and Crowley, 2013). Therefore, the gold standard of these animal phenotypes contains (considerable) intrinsic measurement errors as well as underlying assumptions (i.e., maintenance requirements are a function of metabolic live weight). Errors include, for example, the contribution of gut fill to animal live weight, or the approximation of empty BW (Banos and Coffey, 2010) as an approach to remove the contribution of gut fill to measured animal live weight. Diurnal variability in live weight, however, is likely to exist. Although information is lacking in dairy cows, Currie et al. (1989), using a data set of 40 growing steers on pasture, reported considerable within-day variability in live weight when measured with an automatic scales; the average range in live weight for any given day for a single specific steer, as an example, was $22.4 \mathrm{~kg}$, with the maximum range within a single day being $40 \mathrm{~kg}$ (the steer was approximately $385 \mathrm{~kg}$ on this day, therefore the range was $>10 \%$ of the mean). Body condition score is also a subjective measure of body fat depth (Roche et al., 2009 ) and inter- and intraindividual variability in scoring is likely to exist (Veerkamp et al., 2002). An additional source of error in the definition of feed efficiency (or related traits such as EB) is the estimated regression coefficients of the statistical model used in the derivation of the phenotype of interest such as REI (Robinson, 2005). The accuracy of predicting the index traits of EB and REI was poorer than the accuracy of predicting energy intake across studies (McParland et al., 2011, 2012, 2014). However, error is also likely to exist in the measurement of both DMI (as opposed to feed offered) as well as the energy content of the diet ingested. Such errors in the estimation of feed intake are likely to be exacerbated in grazing production systems, in which grass feed intake is estimated using indigest- 
ible plant components such as $n$-alkanes (Mayes et al. 1986; Dove and Mayes 1991). Similarly, diet selection may exist when more than one animal has access to the same feed station or pasture. Overall, the gold standard measures of feed intake and efficiency are likely to contain considerable inaccuracies and thus achieving very high accuracy of prediction will prove difficult.

\section{Size of the Available Data Set}

Accurate and robust prediction equations are predicated on, among other things, having a large data set from which to derive the prediction equations. The cost of accurately measuring, in particular, feed intake in lactating dairy cows hinders the generation of large data sets especially from different cows (as opposed to serial measurements on the same cow). For accurate quantification of $\mathrm{EB}$, for example, calorimetric chambers are required and throughput is therefore expected to be slow, resource-intensive, and costly, resulting in a small calibration data set. Small data set sizes also affect the robustness of the validation of the equations, as a dilemma exists as to whether to maximize the size of the calibration data set to generate accurate and robust prediction equations or maximize the size of the validation data set to ensure a scientifically sound validation. The accuracy of FTIR-based prediction models generated from cross-validation tends to be superior, almost always, to external validation irrespective of trait (McParland et al., 2011, 2012, 2014; Hempstalk et al., 2015; McDermott et al., 2016; Visentin et al., 2015).

McParland et al. (2011, 2014) undertook an external validation by splitting a single data set into samples used exclusively for model calibration and separate samples exclusively for validation. However, samples in the external and calibration data sets were from the same population and sampling dates. It is crucial that any prediction model is properly validated and this generally requires validation in a completely independent data set. To date, only one study (McParland et al., 2012) has attempted to externally validate equations to predict energy intake and EB on an independent data set. Equations were developed using a research herd of Holsteins fed a TMR diet and milked thrice daily in Scotland and validated on an Irish research herd of grazing Holstein-Friesians milked twice daily. Results from that study showed that despite high accuracy of cross validation $\left(\mathbf{r}_{\mathrm{CV}}\right)$, ranging from 0.87 to 0.88 [root mean square error (RMSE) <23.40 MJ] for energy intake, accuracy in external validation $\left(\mathbf{r}_{\mathrm{V}}\right)$ was poor and ranged from 0.21 to 0.27 (RMSE $<25.96 \mathrm{MJ}$ ). A similar reduction in prediction accuracy was reported for $\mathrm{EB}$ when equations were externally validated in the grazing population of Holstein-Friesians (McParland et al., 2012).

\section{Heterogeneity in Factors Contributing to Animal Phenotypes}

Energy intake, feed efficiency, or indeed EB are not homogeneous phenotypes, in that animals may achieve the same energy intake with a different diet composition (i.e., greater intake of a lower energy diet or a lesser intake of a higher energy diet); moreover, factors other than energy (e.g., protein intake, mineral balance) may also interact with the effect of energy intake on detectable compounds in the milk. This phenomenon is further exacerbated in index traits such as REI or EB, which are a combination of several different traits; for example, 2 dairy cows can have the same REI but have very different energy intake if differences in milk production, live weight, or any of the other energy sinks also differ among animals (Berry and Crowley, 2013). Likewise, multiple factors contribute to whether or not an insemination results in pregnancy, making the prediction of pregnancy (from milk FTIR or other factors) very difficult (Hempstalk et al., 2015). Furthermore, the accuracy of validation of prediction equations across different production systems is likely to be affected by such issues - contrasting diets or animals of different size or yield potential, for example, can result in animals achieving the same phenotypic value from dramatically different underlying principles. Milk quality-based traits, on the other hand, are generally more homogeneous; milk $\mathrm{pH}$ for example is simply the $\mathrm{pH}$ of the milk.

\section{PREDICTION MODELS}

Prediction models are generally developed using cross-validation in a calibration or reference data set and should ideally be externally validated in an independent data set. The most commonly used statistics to determine the precision and robustness of the developed prediction models include the coefficient of determination in cross validation $\left(\mathbf{R}^{2}{ }_{\mathrm{cv}}\right)$ or validation $\left(\mathbf{R}^{2}{ }_{v}\right)$, the accuracy of cross $\left(r_{c v}\right)$ or external validation $\left(\mathrm{r}_{\mathrm{v}}\right)$; that is, the square root of the coefficient of determination, and the standard error of calibration, cross validation, and external validation. The linear regression coefficient of the gold standard measure on the predicted values should also be estimated, as it should be close to unity with an intercept of near zero. The bias in prediction (i.e., the average difference between the gold standard measure and predicted values) is also important, because if prediction bias for 
EB exists, producers may be instructed that their cows are in negative energy balance and that remedial action is warranted, when, in fact, the cows were truly not in negative energy balance.

\section{Pretreatment}

Spectral data are sometimes pretreated to sharpen the absorbance bands of the spectra in an attempt to strengthen the relationship between the infrared spectrum and the gold standard phenotype. The commonly performed spectral pretreatments were reviewed by De Marchi et al. (2014). McParland et al. (2011) failed to detect an improvement in prediction accuracy of either EB or energy intake when either the first derivative or boxcar smoothing of spectral data was used compared with when no pretreatment of spectral data was applied (McParland et al., 2011). Similarly, Dehareng et al. (2012) did not pretreat spectral data when predicting methane emissions. Nonetheless, unlike the studies of Soyeurt et al. (2011, 2012), which found merit in the use of spectral pretreatment, only one spectrometer was used in the studies of Dehareng et al. (2012) and McParland et al. (2011) and therefore the effect of pretreatment of spectral data on accuracy of prediction should still be investigated.

\section{Additional Predictor Variables}

The main advantage of using the FTIR spectrum as a predictor tool is its immediate and relatively seamless integration into the milk recording system. Thus, information other than just the FTIR spectrum may also exist, which could be incorporated into the prediction equations to strengthen the predictability. Including milk yield for example, which is also recorded during milk testing, has been reported to improve the accuracy of prediction of both energy intake and EB in dairy cows (McParland et al., 2011, 2012, 2014).

\section{Prediction Algorithms}

Partial least squares regression analysis is a dimension reduction technique and is the most commonly used statistical approach in the development of prediction equations using FTIR spectral data from milk (McParland et al., 2011; Soyeurt et al., 2011; De Marchi et al., 2014). The number of factors included in the partial least squares models varies from 8 to 20 (McParland et al., 2011, 2012, 2014). Several alternative statistical algorithms have been used in relating infrared spectral data to phenotypes of interest. Hempstalk et al. (2015) evaluated 8 alternative machine-learning algorithms when attempting to relate milk FTIR spectral data to the likelihood of conception in dairy cows. The algorithms evaluated included C4.5 Decision Trees, naïve Bayes, Bayesian network, support vector machines, partial least squares, logistic regression (implemented using a machine-learning framework), and both random and rotation forest; logistic regression was generally the best performing algorithm (Hempstalk et al., 2015). No statistical algorithm other than partial least squares has been used when attempting to predict the energy intake complex from milk FTIR in dairy cows (McParland et al., 2011, 2012, 2014).

\section{Stage of Lactation}

Energy intake and EB are lactation stage dependent. In early lactation, animals cannot consume sufficient energy to meet the energy requirements of lactation, resulting in negative energy balance (Berry et al., 2006), which affects subsequent reproductive performance (Beam and Butler, 1999). Buttchereit et al. (2010) documented a stronger correlation between fat-toprotein ratio and $\mathrm{EB}$ in early lactation $(\mathrm{DIM}=35 ; \mathrm{r}=$ $-0.42)$ than in later lactation (DIM $=175 ; \mathrm{r}<-0.15)$. McParland et al. (2011) also documented a stronger correlation between fat-to-protein ratio and EB in early lactation (DIM $<61 ; \mathrm{r}=-0.28$ ) compared with the correlation estimated using data from all stages of lactation $(\mathrm{r}=-0.09)$. Despite this, accuracy of predicting EB and energy intake directly from the FTIR spectrum did not improve when analysis was limited to only records from early lactation (McParland et al., 2011), although the accuracy of predicting REI improved slightly when predictions were generated using data from early lactation compared with those generated using data across all stages of lactation (McParland et al., 2014). Nonetheless, the data sets used to calibrate the prediction equations were smaller (less than $25 \%$ of the entire data set) when only early lactation records were considered (McParland et al., 2011, 2012, 2014) and this may have affected the accuracy and robustness of the developed equations.

\section{ACCURACY OF PREDICTING ENERGY INTAKE AND EFFICIENCY}

To date, all studies to predict energy intake and efficiency have been undertaken by one research group using data from just 2 populations of lactating Holstein(Friesian) dairy cows (McParland et al., 2011, 2012, 2014). One data set comprised data from a population of UK Holstein cows housed indoors and fed a TMR diet (McParland et al., 2011, 2012); the other data set comprised data from grazing Holstein-Friesian cows in Ireland. A paucity of individual animal energy in- 
take data with corresponding milk FTIR-spectroscopy data is the main limiting factor to generating FTIR prediction equations for energy intake and efficiency in dairy cows. Soyeurt et al. (2011) documented the ability to collate both milk quality data and FTIR data from several countries and use in the development and validation of more robust prediction equations for milk fatty acid content. Berry et al. (2014) summarized how individual animal feed intake data from several international sources could be appropriately combined. Thus, combining individual cow feed intake data and corresponding milk FTIR data from different sources should be possible as a strategy to improve the accuracy, robustness, and therefore applicability of milk FTIR prediction equations for energy intake and efficiency, albeit with all the aforementioned associated nuances associated with the merging of data from alternative sources.

\section{Energy Intake}

Accuracy of prediction (r) of energy intake from milk FTIR in cross validation and external validation across all studies undertaken is presented in Figure 2. Although Figure 2 represents only 2 populations, the results are generated from 3 studies with different, albeit overlapping, data sets. McParland et al. (2011, 2012,2014 ) used data from a single milk sample [morning, midday (McParland et al., 2011), or evening] to make predictions; McParland et al. (2014) used data combined from concurrent evening and morning milk samples to make predictions. When a single milk sample was used for prediction, energy intake was more accurately predicted for cows fed TMR in confinement compared with the grazing cows. Accuracy $\left(\mathrm{r}_{\mathrm{CV}}\right)$ of predicting energy intake in the TMR-fed cows ranged from 0.73 (RMSE <30 MJ; predicted using just the FTIR spectrum of a single milk sample; McParland et al., 2011) to 0.88 (RMSE $=20 \mathrm{MJ}$; predicted using a single milk sample with milk yield; Figure 2; McParland et al., 2011, 2012). Accuracy $\left(\mathrm{r}_{\mathrm{CV}}\right)$ of predicting energy intake in the grazing dairy cows ranged from 0.64 (RMSE $=28.6 \mathrm{MJ}$; predicted using just the FTIR spectrum of a single milk sample; McParland et al., 2014) to 0.76 (RMSE $=23.8 \mathrm{MJ}$; predicted using both morning and evening milk samples combined along with milk yield; Figure 2; McParland et al., 2014). Including milk yield as a predictor of energy intake in the indoor-fed cows yielded an average improvement in $\mathrm{r}_{\mathrm{CV}}$ of 0.13 ; improvement in $\mathrm{r}_{\mathrm{V}}$ was 0.16 (McParland et al., 2011, 2012). In the grazing dairy cows, inclusion of milk yield also improved $r_{C V}$ of energy intake (McParland et al., 2012, 2014). However, the benefit of including milk yield as a predictor variable was less conclusive for the grazing population in external validation (Figure 2 ). External validation data sets were smaller for the grazing population ( $\mathrm{n}=214$ to 406$)$ compared with the TMR population $(\mathrm{n}=433$ to 739$)$.

The TMR-fed confinement population also benefitted from a larger calibration data set with DMI recorded routinely using HOKO feeders (Hokofarm Group BV, Marknesse, the Netherlands). Energy intake in the grazing cows was measured using the $n$-alkane technique, which is based on the ratio of $n$-alkane content in the cow feces relative to that in the herbage. Herbage samples are manually collected to be as representative as possible of what the grazing cow will consume. Good concordance exists between the mean estimated feed intake of the experimental herds and herbage disap-
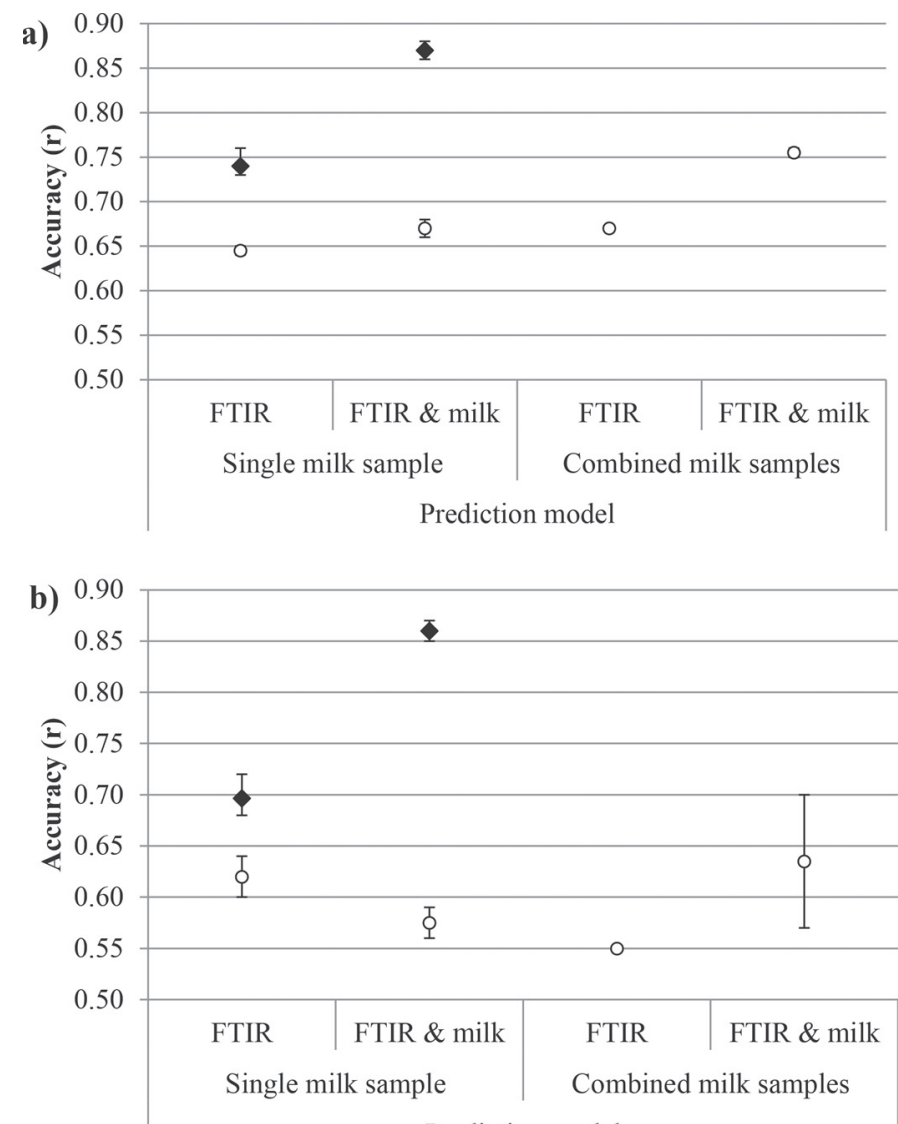

Prediction model

Figure 2. Accuracy of prediction (r) of energy intake in cross validation (a) and external validation (b) from alternative predictive models across 2 populations: cows housed indoors on a TMR diet $(\bullet)$ and cows housed outdoors on a grass-based diet $(\bigcirc)$. Prediction models were based on including only Fourier transform infrared spectral data as a predictor (FTIR), or using both Fourier transform infrared spectral data and milk yield as predictors (FTIR \& milk). Prediction models were based on data from a single morning, midday, or evening milk sample (single milk sample) or from both morning and evening milk samples (combined milk samples). Error bars represent the maximum and minimum accuracy values across studies. 

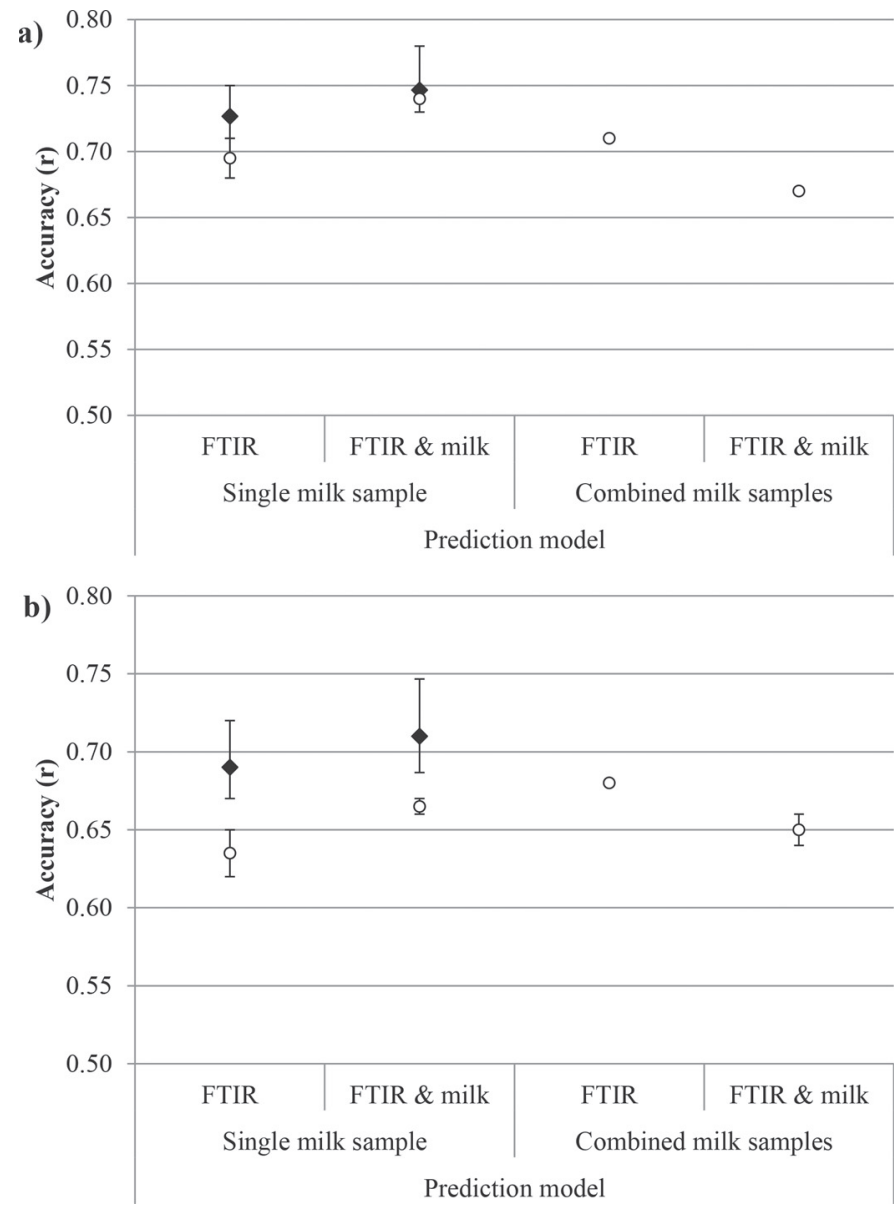

Figure 3. Accuracy of prediction (r) of energy balance in cross validation (a) and external validation (b) from alternative predictive models across 2 populations: cows housed indoors on a total mixed ration diet $(\checkmark)$ and cows housed outdoors on a grass-based diet $(\bigcirc)$. Prediction models were based on including only Fourier transform infrared spectral data as a predictor (FTIR), or using both Fourier transform infrared spectral data and milk yield as predictors (FTIR \& milk). Prediction models were based on data from a single morning, midday, or evening milk sample (single milk sample) or from both morning and evening milk samples (combined milk samples). Error bars represent the maximum and minimum accuracy values across studies.

pearance rate at a herd level (Ganche et al., 2014). Nonetheless, discrepancies at the individual cow level due to factors such as diet selection are likely to exist, thereby affecting the accuracy of individual cow feed intake and energy intake.

\section{Energy Balance}

Accuracy of prediction ( $\mathrm{r}$ ) of EB in cross validation and external validation across all available studies is presented in Figure 3. Across studies, EB was more poorly predicted than energy intake, although the difference in prediction accuracy between populations was small (Figure 3; McParland et al., 2012, 2014). Overall, the $\mathrm{r}_{\mathrm{CV}}$ ranged from 0.67 (RMSE $<24.9 \mathrm{MJ}$; predicted using both morning and evening milk samples together with milk yield in the grazing population; McParland et al., 2014) to 0.78 (RMSE $=18.6 \mathrm{MJ}$; predicted using a single milk sample plus milk yield in the TMR-fed confinement population; McParland et al., 2011). The inclusion of milk yield as an independent variable in the prediction model improved the accuracy of prediction of $\mathrm{EB}$ in the confinement population only by 0.02 to 0.03 units.

\section{Feed Efficiency}

Residual energy intake was best predicted using combined FTIR data from concurrent evening and morning milk samples; $\mathrm{r}_{\mathrm{CV}}$ ranged from 0.50 $(\mathrm{RMSE}=$ $25.3 \mathrm{MJ}$ ) to $0.63(\mathrm{RMSE}=22.0 \mathrm{MJ}$; McParland et al., 2014). External validation accuracy was slightly lower and ranged from 0.48 (RMSE $=26.48 \mathrm{MJ}$ ) to 0.60 $(\mathrm{RMSE}=23.39 \mathrm{MJ}$; McParland et al., 2014). Adding milk yield to the prediction model did not improve the accuracy of prediction, which is not surprising given that REI will be phenotypically independent of milk yield when estimated using least squares regression, as was undertaken by McParland et al. (2014). However, when REI was calculated using the multiple regression model but substituting actual energy intake with FTIRpredicted energy intake, the correlation with true REI was slightly stronger $\left(r_{V}=0.63\right)$ than when predicted directly from the FTIR spectrum (maximum $\mathrm{r}_{\mathrm{V}}=0.60$; McParland et al., 2014), suggesting the former to be a better approach to estimating REI. Nonetheless, feed efficiency and the other animal-level phenotypes such as energy intake and EB were not as well predicted from the FTIR spectrum as has been achieved for milk fatty acid content (Figure 1).

\section{RECOMMENDATIONS FOR DEVELOPMENT OF PREDICTION EQUATIONS}

Soyeurt et al. (2011) demonstrated the benefit to equation accuracy and robustness from having a large calibration data set comprising lots of variability in both the gold standard measures and spectra. McParland et al. (2012) further demonstrated how the use of prediction equations is limited to sample populations that exhibit similar spectral variability to the data used to calibrate prediction equations. To date, equations developed to predict intake and efficiency, although moderately accurate, contain limited variability, and are therefore not immediately applicable to most populations. Indeed, equations have been developed using data from both Holsteins (McParland et al., 2011, 
2012) and Holstein-Friesians (McParland et al., 2012, 2014) only, albeit on contrasting production systems (McParland et al., 2011, 2012, 2014). As already discussed, access to large quantities of individual animal feed intake data hinders the accuracy of equations to predict intake and efficiency. Existing equations would benefit from collaboration between parties with access to both energy intake and FTIRS data on individual animals. Alternatively, populations could develop population-specific equations based on their own data sets.

For true validation, prediction equations should be applied to a population completely independent of that from which they were generated. McParland et al. (2012) attempted to validate in a population of grazing cows, equations developed from a population of cows fed a TMR diet in confinement. However, the accuracy of prediction when equations were calibrated on the confinement data set and validated on the grazing data set was poor and it was concluded that prediction equations should only be applied to populations with similar spectral patterns to what was represented in the calibration data set (McParland et al., 2012). The Mahalanobis distance can be calculated for each spectrum of interest relative to the calibration spectral data, and spectra deviating considerably from the calibration spectrum may not be predicted or should be provided under caution.

Limited data sets with access to both individual animal energy intake and FTIR spectroscopy of milk samples exist, inhibiting external validation across populations of the prediction equations developed. This is an active area of research, and several research teams internationally are working to gather such data sets in an attempt to (1) strengthen and validate prediction equations of energy intake and efficiency, and (2) develop additional population-specific prediction equations. A spectral data set of samples with energy intake data already exists. Routinely generated spectra should be compared with this spectral data set (e.g., Mahalanobis distance), and animals with a spectrum deviating from the data set identified. These animals should subsequently be phenotyped for energy intake, $\mathrm{EB}$, and REI. Because these animal-related traits are repeatable (Berry et al., 2007), measures taken several days or weeks (or parities) later are still likely to be informative. From a genetic evaluations perspective, different genetic families should ideally be represented in the calibration data set to facilitate a more precise estimate of the genetic correlation between the true and predicted animal characteristics for inclusion in the selection index. In addition, participating bodies should harmonize their definition of the gold standard measures, participate in ring-testing of their spectrometers, and harmonize all spectrometers. Care should be taken, however, in adding too much variability because the leverage of some samples on the regression may actually reduce the general applicability of the developed prediction equations. Consideration should be given to using only spectra in the calibration process that resemble the spectra where the equations will be applied; this therefore potentially implies a different calibration data set for different situations although comparability of predictions must exist. One possible (simple) option is to have a set of samples common to each predicted data set and adjust all predictions accordingly so that the mean prediction and variability of the common samples remains constant.

\section{APPLICATION OF PREDICTION MODELS IN DAIRY PRODUCTION}

\section{Genetic Selection}

A trait must fulfill 3 criteria before consideration for inclusion in a breeding goal. The trait must

1. Be important - this could be economically, socially, or environmentally important;

2. Exhibit genetic variation - even if lowly heritable, once genetic variation is present, then genetic gain is possible;

3. Be (ideally easily and inexpensively) measureable or genetically correlated with a heritable measureable trait.

Feed costs constitute a large proportion of dairy production costs globally (Shalloo et al., 2004; Ho et al., 2005), confirming the economic importance of the feed intake complex. Wall et al. (2008) documented the economic value for energy balance in dairy production systems. Additionally, producing more human-edible animal-derived protein and energy sources more efficiently is not only socially important but also important in minimizing the environmental footprint of modern-day dairy production systems (Berry et al., 2015). Energy balance is known to be associated with compromised health and fertility in dairy cows (Beam and Butler, 1999; Collard et al., 2000), the latter being of growing concern among modern-day consumers. Therefore, not only do energy intake and EB have (economic) value in their own right but they may also be useful as (early) predictors of other economically important traits within a selection index framework.

The presence of ample genetic variation in the feed intake complex has already been extensively discussed (Berry and Crowley, 2013). Therefore, routine access to phenotypic information from which to derive genetic evaluations is heretofore the only factor hindering the 


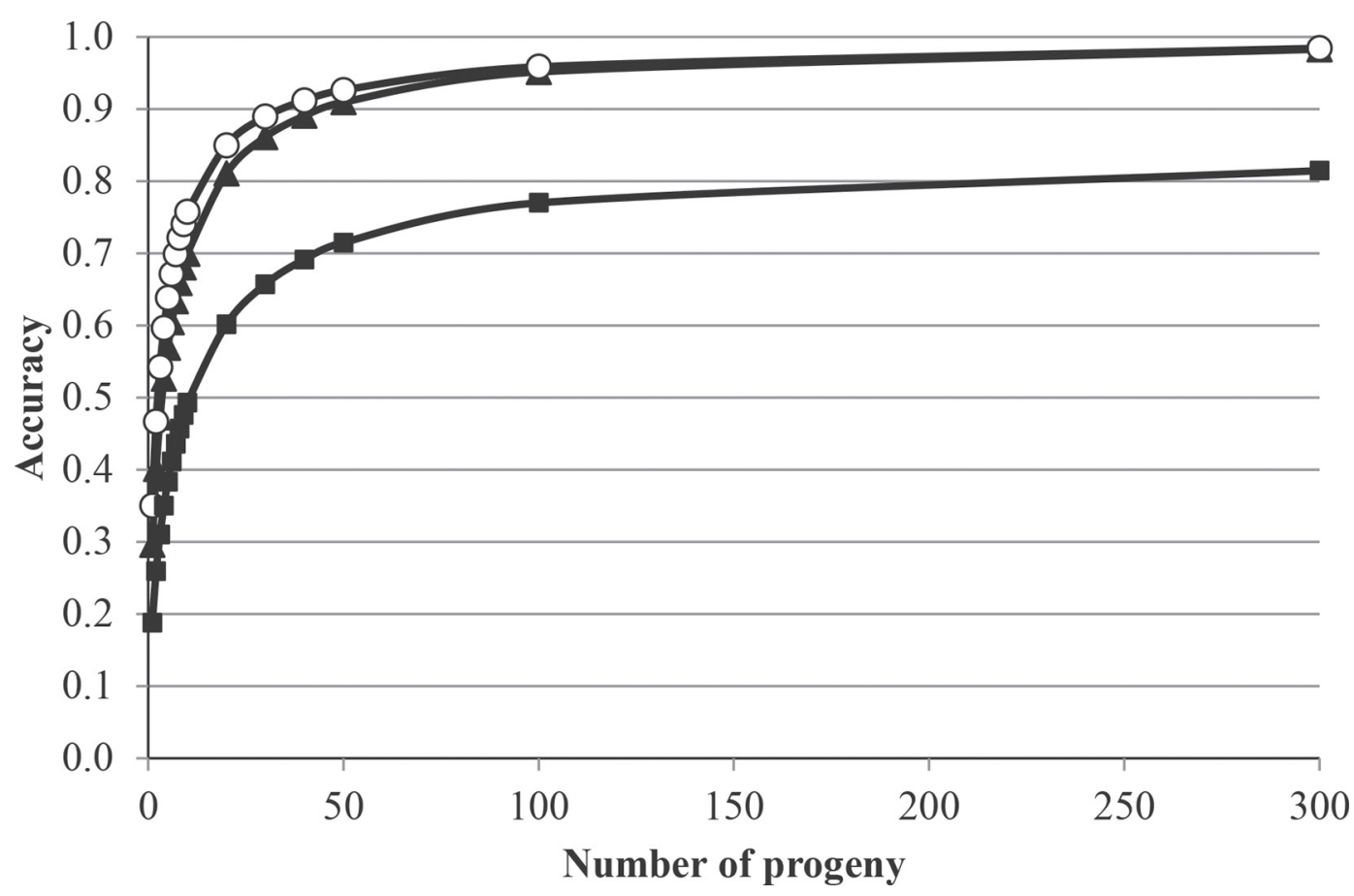

Figure 4. Accuracy of selection for true energy intake across different numbers of progeny with records for Fourier transform infrared (FTIR)-predicted energy intake alone , true energy intake $(\boldsymbol{\Lambda})$, or both true and FTIR-predicted feed intake combined $(\bigcirc)$.

inclusion of the traits related to the feed intake complex in dairy breeding programs. This is important even in the current environment where genomic evaluations prevail in most national genetic evaluations because routine access to accurate phenotypes is still an important requirement to underpin genomic prediction accuracy. Berry and Crowley (2013) documented the usefulness of selection index theory for predicting genetic merit for feed intake using a selection of routinely measured traits such as milk yield, live weight, and type traits; Berry and Crowley (2013) conceded, however, that their approach was not (fully) capturing genetic variability in net feed efficiency. Figure 4 illustrates the accuracy of selection for true energy intake based on the respective FTIR-predicted values of energy intake; the phenotypic and genetic parameters used in the selection index calculations are in Table 1. In the absence of gold standard measures, the accuracy of selection cannot be greater than the genetic correlation between the gold standard and predicted values (i.e., 0.84; McParland et al., 2015). The underlying assumption here, however, is that the gold standard measure is in fact just that, and no errors in measurement (i.e., energy intake) or calculation (i.e., energy balance, REI) exist, although this is likely to also be reflected in the heritability. Moreover, what is not yet clear is whether the gold standard of EB is actually a better predictor of health and fertility than the FTIR-predicted value of EB; FTIRS may actually be capturing features in the milk that contribute to a stronger genetic correlation with health and fertility. Nonetheless, high accuracy of selection of the gold standard measures is still achievable through indirect selection using the FTIR-predicted phenotypes. Because the FTIR spectrum is routinely generated during milk testing, these data are freely available. For example, FTIR-predicted energy intake on 43 progeny per sire will achieve the same accuracy of selection for the gold standard energy intake measure as 10 progeny per sire with gold standard energy intake measures (Figure 4).

McParland et al. (2015) quantified the genetic variation of FTIR-predicted energy intake and EB and the genetic associations between $\mathrm{EB}$ and energy intake measured either conventionally or predicted using milk FTIR spectroscopy. Heritability of the measured traits was greater than that of the respective FTIR-predicted trait; heritability of measured and predicted EB was 0.16 and 0.10 , respectively, whereas heritability of measured and predicted energy intake was 0.35 and 0.20 , respectively (McParland et al., 2015). This is not unexpected given the lack of unity phenotypic prediction accuracy of the gold standard measures from the FTIR spectrum. Furthermore, the genetic correlation between measured and FTIR-predicted energy intake was 0.84 , and between measured and FTIR-predicted EB was 0.54, indicating that selection on FTIR-predicted energy intake or EB would improve measured energy 
$\sigma_{R E I}^{2}=\left[\begin{array}{c}1 \\ -\operatorname{Cov}(E I, M Y) / \sigma_{M Y}^{2} \\ -\operatorname{Cov}(E I, F Y) / \sigma_{F Y}^{2} \\ -\operatorname{Cov}(E I, P Y) / \sigma_{P Y}^{2} \\ -\operatorname{Cov}(E I, L W) / \sigma_{L W}^{2} \\ -\operatorname{Cov}(E I, B C S) / \sigma_{B C S}^{2}\end{array}\right]$

$\left[\begin{array}{cccccc}\sigma_{E I}^{2} & \ldots & \ldots & \ldots & \ldots & \ldots \\ \operatorname{Cov}(E I, M Y) & \sigma_{M Y}^{2} & \ldots & \ldots & \ldots & \ldots \\ \operatorname{Cov}(E I, F Y) & \operatorname{Cov}(M Y, F Y) & \sigma_{F Y}^{2} & \ldots & \ldots & \ldots \\ \operatorname{Cov}(E I, P Y) & \operatorname{Cov}(M Y, P Y) & \operatorname{Cov}(F Y, P Y) & \sigma_{P Y}^{2} & \ldots & \ldots \\ \operatorname{Cov}(E I, L W) & \operatorname{Cov}(M Y, L W) & \operatorname{Cov}(F Y, L W) & \operatorname{Cov}(P Y, L W) & \sigma_{L W}^{2} & \ldots \\ \operatorname{Cov}(E I, B C S) & \operatorname{Cov}(M Y, B C S) & \operatorname{Cov}(F Y, B C S) & \operatorname{Cov}(P Y, B C S) & \operatorname{Cov}(L W, B C S) & \sigma_{B C S}^{2}\end{array}\right]\left[\begin{array}{c}1 \\ -\operatorname{Cov}(E I, M Y) / \sigma_{M Y}^{2} \\ -\operatorname{Cov}(E I, F Y) / \sigma_{F Y}^{2} \\ -\operatorname{Cov}(E I, P Y) / \sigma_{P Y}^{2} \\ -\operatorname{Cov}(E I, L W) / \sigma_{L W}^{2} \\ -M Y) B C S / \sigma_{B C S}^{2}\end{array}\right]$,

intake or EB, respectively (McParland et al., 2015). McParland et al. (2015) predicted breeding values of FTIR-predicted energy intake for a group of animals with known energy intake. The regression coefficient of known energy intake on predicted breeding values based on FTIR-predicted energy intake was $0.82(\mathrm{SE}=$ $0.25 ; P=0.001$ ), indicating that genetic selection based on FTIR-predicted intake would identify animals with differences in known energy intake.

No heritability estimates for REI predicted from milk FTIR exist in the literature. The genetic variance of REI can, however, be calculated as shown above (Berry et al., 2013b), where (co)variance components refer to the additive genetic (co)variance components estimated in this study, $\sigma=$ variance, and $E I=$ energy intake, $M Y$ $=$ milk yield, $F Y=$ fat yield, $P Y=$ protein yield, $L W=$ live weight, and $B C S=$ body condition score. The phe- notypic variance for REI was calculated using the same approach but substituting phenotypic (co)variance components for the genetic (co)variance components. The variance components used in the calculations are in Table 1. The heritability of REI was calculated based on the derived genetic and phenotypic variances. The proportion of phenotypic variance in true energy intake and predicted energy intake accounted for by milk yield, fat yield, protein yield, live weight, and BCS was 29 and $74 \%$, respectively; the respective statistics for the proportion of genetic variance explained was 91 and $47 \%$. The heritability of REI calculated from true energy intake and FTIR-predicted energy intake was 0.04 and 0.15 , respectively. These estimates are similar to the mean heritability of 0.04 reported by Berry and Crowley (2013) based on a meta-analysis of 7 studies from lactating dairy and beef cows but greater than

Table 1. Genetic standard deviation and heritability of various performance traits ${ }^{1}$ including true and Fourier transform infrared-predicted energy intake, as well as genetic (above diagonal) and phenotypic (below diagonal) correlations among the traits

\begin{tabular}{|c|c|c|c|c|c|c|c|}
\hline Item & $\begin{array}{l}\text { Milk yield } \\
\quad(\mathrm{kg})\end{array}$ & $\begin{array}{l}\text { Fat yield } \\
(\mathrm{kg})\end{array}$ & $\begin{array}{l}\text { Protein } \\
\text { yield }(\mathrm{kg})\end{array}$ & $\begin{array}{c}\text { BCS } \\
\text { (scale } 1 \text { to } 5 \text { ) }\end{array}$ & $\begin{array}{l}\text { Live weight } \\
(\mathrm{kg})\end{array}$ & $\begin{array}{l}\text { True energy } \\
\text { intake (MJ) }\end{array}$ & $\begin{array}{l}\text { Predicted energy } \\
\quad \text { intake (MJ) }\end{array}$ \\
\hline Genetic standard deviation & 352.0 & 18.40 & 11.90 & 0.19 & 33.90 & 14.53 & 11.18 \\
\hline Heritability & 0.28 & 0.44 & 0.32 & 0.58 & 0.60 & 0.35 & 0.20 \\
\hline Milk yield & & 0.29 & 0.73 & -0.46 & -0.01 & 0.69 & 0.50 \\
\hline Fat yield & 0.62 & & 0.62 & -0.30 & 0.03 & -0.07 & 0.08 \\
\hline Protein yield & 0.88 & 0.73 & & -0.43 & -0.03 & 0.03 & 0.05 \\
\hline True energy intake & 0.54 & -0.09 & 0.11 & 0.12 & 0.56 & & 0.84 \\
\hline Predicted energy intake & 0.44 & -0.01 & 0.11 & 0.09 & 0.24 & 0.57 & \\
\hline
\end{tabular}

${ }^{1}$ Genetic parameters and correlations among milk yield, fat yield, protein yield, BCS, and live weight were obtained from Berry et al. (2003) where milk yield $=$ cummilk240, fat yield $=$ cumfat240, protein yield $=$ cumprot240, $\mathrm{BCS}=$ AVGBCS and live weight $=$ AVGBW Genetic parameters and correlations among performance traits and true and predicted energy intake were obtained from McParland et al. (2015). 
the heritability of 0.01 reported more recently (and included in the meta-analysis) in lactating US Holstein cows (Vallimont et al., 2011).

\section{Management}

Achieving optimum day-to-day herd management requires real-time access to data from which to make informed decisions. Ideally, the information should be available across time and at low cost so that alterations in management can be evaluated or signals of forthcoming potential issues can be identified early. Individual animal official milk testing is, however, generally undertaken, at best, every 4 wk. Nonetheless, bulk tank milk samples collected more often (i.e., daily or every 2 to $3 \mathrm{~d}$ ) are also subjected to FTIR analysis and can thus be used to generate information on energy status or feed efficiency at the herd level. Moreover, because NIR detects overtones and combinations of the fundamental bands from the FTIR, the potential also exists to use lower-cost NIR equipment, either at the individual cluster level or at the herd milk-line level to more routinely (i.e., every milking) monitor cow or herd performance. The ability of NIRS to predict cowlevel characteristics needs to be investigated, as has previously been undertaken for milk quality (Coppa et al., 2014).

Routine access to information on cow performance and physiological status opens up considerable opportunities for more detailed precision farming; this is particularly true for grazing production systems where, for example, phenotyping of the pasture in a rotational grazing system could be undertaken based on the performance of the herd (i.e., yield and milk quality). Such information could be used to identify paddocks for reseeding or that may require (tailored) fertilization. Herd energy status predictions could also be used as a guide to whether the recently allocated pasture allowance was sufficient to meet the energy demands of the lactating herd.

Several alternative statistical approaches exist for modeling longitudinal data. Random regression models are now commonly used in the modeling of longitudinal data in dairy cow genetic studies (Berry et al., 2003, 2006); in dairy cattle, these random regression models on milk production are commonly termed "test-day models." A fixed regression is fitted to model the underlying mean of the population or sub-population (e.g., parity); individual animal deviations from the fixed regression are modeled using random regressions, which are sometimes partitioned into an additive genetic effect and a permanent environmental effect. Summing the individual animal's daily random effects and the associated fixed effects generates an animal-specific lactation profile, which can be used to interpolate between test-days. The advantage of this approach is that not only is it useful for day-to-day herd management but the additive genetic random regression coefficients can be used in breeding programs to select for animals with more favorable lactation profile characteristics (i.e., total milk yield, persistent lactations). Moreover, the herd-level solutions are a good representation of herd management because they are independent of the genetic merit of the animals on the farm, as well as other potential confounding effects in the model (e.g., herd age structure). Such information can be used to benchmark herds against each other, and supplementary data available (e.g., diet type) can be subsequently used in an attempt to decipher why inter-herd performance differences exist. Bastin et al. (2009) applied random regression methodology to the modeling of milk urea nitrogen in milk (predicted from FTIR), which they suggested could be used in decision-support tools.

\section{CONCLUSIONS}

Routine access to accurate information is fundamental to informed management and breeding decisions. Such information should ideally be available at low cost and not impinge on day-to-day herd management. Infrared spectroscopic analysis of milk is a nondestructive technique that could be implemented in-line to provide real-time information or cow or herd status, in the future. The accuracy (r) of predicting energy intake, energy balance, and feed efficiency in dairy cows reached $0.88,0.78$, and 0.63 , respectively, based on cross-validation. Accuracy of prediction in a completely external validation data set based on production systems not represented in the validation data set was, as expected, poor. Expansion in variability within the data set used to generate the prediction equations is therefore required to ensure greater robustness of the developed prediction equations and applicability to a wider population.

\section{ACKNOWLEDGMENTS}

Funding from the Irish Department of Agriculture, Food and the Marine (Dublin, Ireland), Research Stimulus Fund projects 13/S/96, RAPIDFEED, and 11/ $\mathrm{SF} / 311$, BREEDQUALITY is gratefully acknowledged.

\section{REFERENCES}

Banos, G., and M. P. Coffey. 2010. Genetic association between body energy measured throughout lactation and fertility in dairy cattle. Animal 4:189-199. 
Barber, M. C., R. A. Clegg, M. T. Travers, and R. G. Vernon. 1997. Lipid metabolism in the lactating mammary gland. Biochim. Biophys. Acta 1347:101-126.

Bastin, C., L. Laloux, A. Gillon, F. Miglior, H. Soyeurt, H. Hammami, C. Bertozzi, and N. Gengler. 2009. Modelling milk urea of Walloon dairy cows in management perspectives. J. Dairy Sci. 92:3529-3540.

Beam, S. W., and W. R. Butler. 1999. Effects of energy balance on follicular development and first ovulation in postpartum dairy cows. J. Reprod. Fertil. Suppl. 54:411-424.

Berry, D. P., F. Buckley, P. G. Dillon, R. D. Evans, M. Rath, and R. F. Veerkamp. 2003. Genetic relationships among body condition score, body weight, milk yield, and fertility in dairy cows. J. Dairy Sci. 86:2193-2204

Berry, D. P., M. P. Coffey, J. E. Pryce, Y. De Haas, P. Lovendahl, N. Krattenmacher, J. J. Crowley, Z. Wang, D. Spurlock, K. Weigel, K. MacDonald, and R. F. Veerkamp. 2014. International genetic evaluations for feed intake in dairy cattle through the collation of data from multiple sources. J. Dairy Sci. 97:3894-3905.

Berry, D. P., J. Coyne, B. Coughlan, M. Burke, J. McCarthy, A. R. Cromie, and S. McParland. 2013b. Genetics of milking characteristics in dairy cows. Animal 7:1750-1758.

Berry, D. P., and J. J. Crowley. 2013. Genetics of feed efficiency in dairy and beef cattle. J. Anim. Sci. 91:1594-1613.

Berry, D. P., B. Horan, M. O'Donovan, F. Buckley, E. Kennedy, M. McEvoy, and P. G. Dillon. 2007. Genetics of grass dry matter intake, energy balance, and digestibility in grazing Irish dairy cows. J. Dairy Sci. 90:4835-4845.

Berry, D. P., E. Kennedy, and J. J. Crowley. 2015. Genetics of feed intake and reproduction. Pages 502-522 in The Genetics of Cattle. D. J. Garrick and A. Ruvinsky, ed. CABI, Wallingford, UK.

Berry, D. P., S. McParland, C. Bastin, E. Wall, N. Gengler, and H. Soyeurt. 2013a. Phenotyping of robustness and milk quality. Pages 600-605 in Advances in Animal Biosciences. Vol. 4. Cambridge University Press, Cambridge, UK

Berry, D. P., R. F. Veerkamp, and P. G. Dillon. 2006. Phenotypic profiles for body weight, body condition score, energy intake, and energy balance across different parities and concentrate feeding levels. Livest. Sci. 104:1-12.

Bonfatti, V., G. Di Martino, and P. Carnier. 2011. Effectiveness of mid-infrared spectroscopy for the prediction of detailed protein composition and contents of protein genetic variants of individual milk of Simmental cows. J. Dairy Sci. 94:5776-5785.

Buttchereit, N., E. Stamer, W. Junge, and G. Thaller. 2010. Evaluation of five lactation curve models fitted for fat: protein ratio of milk and daily energy balance. J. Dairy Sci. 93:1702-1712.

Byerly, T. C. 1941. Feed and other costs of producing market eggs. Bulletin A1 (Technical). The University of Maryland Agricultural Experiment Station, College Park.

Chilliard, Y., A. Ferlay, and M. Doreau. 2001. Effect of different types of forages, animal fat or marine oils in cow's diet on milk fat secretion and composition, especially conjugated linoleic acid (CLA) and polyunsaturated fatty acids. Livest. Sci. 70:31-48.

Coleman, J., D. P. Berry, K. M. Pierce, A. Brennan, and B. Horan. 2010. Dry matter intake and feed efficiency profiles of 3 genotypes of Holstein-Friesian within pasture-based systems of milk production. J. Dairy Sci. 93:4318-4331.

Collard, B. L., J. C. M. Dekkers, D. Petitclerc, and L. R. Schaeffer. 2000. Relationships between energy balance and health traits of dairy cattle in early lactation. J. Dairy Sci. 83:2683-2690.

Coppa, M., A. Revello-Chion, D. Giaccone, A. Ferlay, E. Tabacco, and G. Borreani. 2014. Comparison of near and medium infrared spectroscopy to predict fatty acid composition on fresh and thawed milk. Food Chem. 150:49-57.

Currie, P. O., J. D. Volesky, D. C. Adams, and B. W. Knapp. 1989. Growth patterns of yearling steers determined from daily live weights. J. Range Manage. 42:393-396.

Daetwyler, H. D., B. Villanueva, and J. A. Woolliams. 2008. Accuracy of predicting the genetic risk of disease using a genome-wide approach. PLoS ONE 3:e3395.
Dal Zotto, R., M. De Marchi, A. Cecchinato, A. Penasa, M. Cassandro, P. Carnier, L. Gallo, and G. Bittante. 2008. Reproducibility and repeatability of measures of milk coagulation properties and predictive ability of mid-infrared reflectance spectroscopy. J. Dairy Sci. 91:4103-4112.

De Marchi, M., C. C. Fagan, C. P. O'Donnell, A. Cecchinato, R. Dal Zotto, M. Cassandro, M. Penasa, and G. Bittante. 2009. Prediction of coagulation properties, titratable acidity, and $\mathrm{pH}$ of bovine milk using mid-infrared spectroscopy. J. Dairy Sci. 92:423-432.

De Marchi, M., V. Toffanin, M. Cassandro, and M. Penasa. 2014. Invited Review: Mid-infrared spectroscopy as a phenotyping tool for milk traits. J. Dairy Sci. 97:1171-1186.

de Roos, A. P. W., H. J. C. M. van den Bijgaart, J. Hørlyk, and G. De Jong. 2007. Screening for subclinical ketosis in dairy cattle by Fourier transform infrared spectroscopy. J. Dairy Sci. 90:1761-1766.

Dehareng, F., C. Delfosse, E. Froidmont, H. Soyeurt, C. Martin, N. Gengler, A. Vanlierde, and P. Dardenne. 2012. Potential use of milk mid-infrared spectra to predict individual methane emission of dairy cows. Animal 6:1694-1701

Dove, H., and R. W. Mayes. 1991. The use of plant wax alkanes as marker substances in studies of the nutrition of herbivores: A review. Aust. J. Agric. Res. 42:913-952.

Edney, M. J., J. E. Morgan, P. C. Williams, and L. D. Campbell. 1994. Analysis of feed barley by near infrared reflectance technology. J. Near Infrared Spectrosc. 2:33-41.

Friggens, N. C., P. Berg, P. Theilgaard, I. R. Korsgaard, K. L. Ingvartsen, P. Løvendahl, and J. Jensen. 2007. Breed and parity effects on energy balance profiles through lactation: Evidence of genetically driven body energy change. J. Dairy Sci. 90:5291-5305.

Ganche, E., L. Delaby, M. O'Donovan, T. M. Boland, and E. Kennedy. 2014. Short-term response in milk production, dry matter intake, and grazing behavior of dairy cows to changes in postgrazing sward height. J. Dairy Sci. 97:3028-3041.

Grieve, D. G., S. Korver, Y. S. Rijpkema, and G. Hof. 1986. Relationship between milk composition and some nutritional parameters in early lactation. Livest. Sci. 14:239-254.

Hansen, P. W. 1999. Screening of dairy cows for ketosis by use of infrared spectroscopy and multivariate calibration. J. Dairy Sci. 82:2005-2010

Hempstalk, K., S. McParland, and D. P. Berry. 2015. Machine learning algorithms for the prediction of conception success to a given insemination in lactating dairy cows. J. Dairy Sci. 98:5262-5273.

Heuer, C., H. J. Luinge, E. T. G. Lutz, H. Schukken, J. H. van der Maas, H. Wilmink, and J. P. T. M. Noordhuizen. 2001. Determination of acetone in cow milk by Fourier transform infrared spectroscopy for the detection of subclinical ketosis. J. Dairy Sci. $84: 575-582$.

Ho, C., R. Nesseler, P. Doyle, and B. Malcolm. 2005. Future dairy farming systems in irrigation regions. Aust. Farm Bus. Manage. J. 2:59-68.

Hummel, J. W., K. A. Sudduth, and S. E. Hollinger. 2001. Soil moisture and organic matter prediction of surface and subsurface soils using an NIR soil sensor. Comput. Electron. Agric. 32:149-165.

Hurley, A. M., N. López-Villalobos, S. McParland, E. Kennedy, E. Lewis, M. O'Donovan, J. L. Burke, and D. P. Berry. 2016. Interrelationships among alternative definitions of feed efficiency in grazing lactating dairy cows. J. Dairy Sci. 99:468-479.

Jarrige, R., C. Demarquilly, J. P. Dulphy, A. Hoden, J. Robelin, C. Beranger, Y. Geay, M. Journet, C. Malterre, D. Micol, and M. Petit. 1986. The INRA "fill unit" system for predicting the voluntary intake of forage-based diets in ruminants: A review. J. Anim. Sci. 63:1737-1758.

Johnson, K. A., and D. E. Johnson. 1995. Methane emissions from cattle. J. Anim. Sci. 73:2483-2492.

Kamruzzaman, M., G. ElMasry, D. Sun, and P. Allen. 2012. Nondestructive prediction and visualization of chemical composition in lamb meat using NIR hyperspectral imaging and multivariate regression. Innovative Food Science and Emerging Technologies $16: 218-226$. 
Klein, M. S., N. Buttchereit, S. P. Miemczyk, A. Immervoll, C. Louis, S. Wiedemann, W. Junge, G. Thaller, P. J. Oefner, and W. Gronwald. 2012. NMR metabolomic analysis of dairy cows reveals milk glycerophosphocholine to phosphocholine ratio as prognostic biomarker for risk of ketosis. J. Proteome Res. 11:1373-1381.

Lu, J., E. Antunes Fernandes, A. E. Páez Cano, J. Vinitwatanakhun, S. Boeren, T. van Hooijdonk, A. van Knegsel, J. Vervoort, and K. A. Hettinga. 2013. Changes in milk proteome and metabolome associated with dry period length, energy balance, and lactation stage in postparturient dairy cows. J. Proteome Res. 12:3288-3296.

Luinge, H. J., E. Hop, E. T. G. Lutz, J. A. van Hemer, and E. A. M. de Jong. 1993. Determination of the fat, protein and lactose content of milk using Fourier transform infrared spectrometry. Anal. Chim. Acta 284:419-433.

Maurice-Van Eijndhoven, M. H. T., H. Soyeurt, F. Dehareng, and M. P. L. Calus. 2013. Validation of fatty acid predictions in milk using mid-infrared spectrometry across cattle breeds. Animal 7:348-354.

Mayes, R. W., C. S. Lamb, and P. M. Colgrove. 1986. The use of dosed and herbage $\mathrm{n}$-alkanes as markers for the determination of herbage intake. J. Agric. Sci. (Camb.) 107:161-170.

McDermott, A., G. Visentin, M. De Marchi, D. P. Berry, M. A. Fenelon, P. M. O'Connor, and S. McParland. 2016. Prediction of individual milk proteins including free amino acids in bovine milk using mid-infrared spectroscopy and their correlations with milk processing characteristics. J. Dairy Sci. 99:3171-3182. http:// dx.doi.org/10.3168/jds.2015-9747.

McParland, S., G. Banos, B. McCarthy, E. Lewis, M. P. Coffey, B. O'Neill, M. O'Donovan, E. Wall, and D. P. Berry. 2012. Validation of mid-infrared spectrometry in milk for predicting body energy status in Holstein-Friesian cows. J. Dairy Sci. 95:7225-7235.

McParland, S., G. Banos, E. Wall, M. P. Coffey, H. Soyeurt, R. F Veerkamp, and D. P. Berry. 2011. The use of mid-infrared spectrometry to predict body energy status of Holstein cows. J. Dairy Sci. 94:3651-3661.

McParland, S., E. Kennedy, E. Lewis, S. G. Moore, B. McCarthy, M. O'Donovan, and D. P. Berry. 2015. Genetic parameters of dairy cow energy intake and body energy status predicted using midinfrared spectrometry of milk. J. Dairy Sci. 98:1310-1320.

McParland, S., E. Lewis, E. Kennedy, S. G. Moore, B. McCarthy, S. T. Butler, and D. P. Berry. 2014. Mid-infrared spectrometry of milk as a predictor of energy intake and efficiency in lactating dairy cows. J. Dairy Sci. 97:5863-5871.

NRC. 2001. Nutrient Requirements of Dairy Cattle. 7th rev. ed. Natl. Acad. Sci., Washington, DC.

Palmquist, D. L., A. D. Baulieu, and D. M. Barbano. 1993. Feed and animal factors influencing milk fat composition. J. Dairy Sci. 76:1753-1771.

Reist, M., D. Erdin, D. von Euw, K. Tschuemperlin, H. Leuenberger, Y. Chilliard, H. M. Hammon, C. Morel, C. Philipona, Y. Zbinden, N. Kuenzi, and J. W. Blum. 2002. Estimation of energy balance at the individual and herd level using blood and milk traits in highyielding dairy cows. J. Dairy Sci. 85:3314-3327.

Robinson, D. L. 2005. Accounting for bias in regression coefficients with example from feed efficiency. Livest. Prod. Sci. 95:155-166.

Roche, J. R., N. C. Friggens, J. K. Kay, M. W. Fisher, K. J. Stafford, and D. P. Berry. 2009. Body condition score and its association with dairy cow productivity, health and welfare. J. Dairy Sci. 92:5769-5801.
Rutten, M. J. M., H. Bovenhuis, J. M. L. Heck, and J. A. M. van Arendonk. 2011. Predicting bovine milk protein composition based on Fourier transform infrared spectra. J. Dairy Sci. 94:5683-5690.

Rutten, M. J. M., H. Bovenhuis, K. A. Hettinga, H. J. F. Van Vanlenberg, and J. A. M. Van Arendonck. 2009. Predicting bovine milk fat composition using infrared spectroscopy based on milk samples collected in winter and summer. J. Dairy Sci. 92:6202-6209.

Shalloo, L., P. Dillon, M. Rath, and M. Wallace. 2004. Description and validation of the Moorepark Dairy Systems Model (MDSM). J. Dairy Sci. 87:1945-1959.

Soyeurt, H., C. Bastin, F. G. Colinet, V. M. R. Arnould, D. P. Berry, E. Wall, F. Dehareng, H. N. Nguyen, P. Dardenne, J. Schefers, J. Vandenplas, K. Weigel, M. Coffey, L. Théron, J. Detilleux, E. Reding, N. Gengler, and S. McParland. 2012. MIR prediction of lactoferrin content in bovine milk: Potential indicator of mastitis. Animal 6:1830-1838.

Soyeurt, H., D. Bruwier, J.-M. Romnee, N. Gengler, C. Bertozzi, D. Veselko, and P. Dardenne. 2009. Potential estimation of mineral contents in cow milk using FTIR spectrometry. J. Dairy Sci. 92:2444-2454.

Soyeurt, H., F. Dehareng, N. Gengler, S. McParland, E. Wall, D. P. Berry, M. Coffey, and P. Dardenne. 2011. Mid-infrared prediction of bovine milk fatty acids across multiple breeds, production systems, and countries. J. Dairy Sci. 94:1657-1667.

Toffanin, V., M. De Marchi, N. Lopez-Villalobos, and M. Cassandro. 2014. Effectiveness of mid-infrared spectroscopy for prediction of the contents of calcium and phosphorus, and titratable acidity of milk and their relationship with milk quality and coagulation properties. Int. Dairy J. 41:68-73.

Vallimont, J. E., C. D. Dechow, J. M. Daubert, M. W. Dekleva, J. W. Blum, C. M. Barlieb, W. Liu, G. A. Varga, A. J. Heinrichs, and C. R. Baumrucker. 2011. Short communication: Heritability of gross feed efficiency and associations with yield, intake, residual intake, body weight, and body condition score in 11 commercial Pennsylvania tie stalls. J. Dairy Sci. 94:2108-2113.

Vanlierde, A., M. L. Vanrobays, F. Dehareng, E. Froidmont, H. Soyeurt, S. McParland, E. Lewis, M. H. Deighton, F. Grandl, M. Kreuzer, B. Gredler, P. Dardenne, and N. Gengler. 2015. Hot Topic: Innovative lactation stage dependent prediction of methane emissions from milk mid-infrared spectra. J. Dairy Sci. 98:57405747.

Veerkamp, R. F., C. L. M. Gerritsen, E. P. C. Koenen, A. Hamoen, and G. De Jong. 2002. Evaluation of classifiers that score linear type traits and body condition score using common sires. J. Dairy Sci. 85:976-983.

Visentin, G., A. McDermott, S. McParland, D. P. Berry, O. A. Kenny, A. Brodkorb, M. A. Fenelon, and M. De Marchi. 2015. Prediction of bovine milk technological traits from midinfrared spectroscopy analysis in dairy cows. J. Dairy Sci. 98:6620-6629.

Wall, E., M. P. Coffey, and P. R. Amer. 2008. A theoretical framework for deriving direct economic values for body tissue mobilization traits in dairy cattle. J. Dairy Sci. 91:343-353.

Williams, P. C., and K. H. Norris. 1987. Qualitative applications of near-infrared reflectance spectroscopy. Pages $241-246$ in Near-Infrared Technology in the Agricultural and Food Industries. P. Williams and K. Norris, ed. American Association of Cereal Chemists, St. Paul, MN. 